\title{
Удаленная малая экономика: теоретические основания и эмпирические наблюдения"
}

\author{
Лариса В. Мельникова \\ Институт экономики и организации промышленного производства \\ Сибирского отделения Российской академии наук, Российская Федерация
}

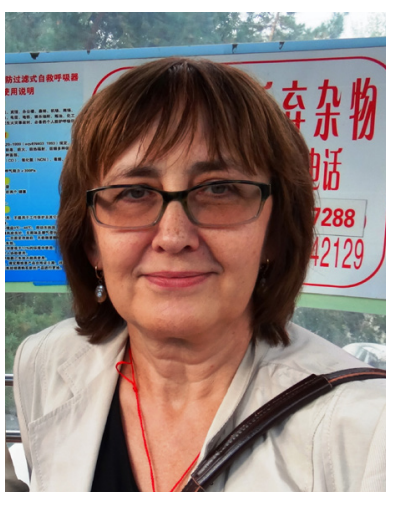

Начиная с 1990-х г2. в экономической литературе не ослабевает внимание к теме влияния географического фактора на экономическую динамику и, отсюда, межстрановое и межрегиональное неравенство. Проблемы изолированных удаленных регионов внутри страны актуальны для стран, отличающихся размером территории и разнообразием природных условий, таких как Россия, Канада, Австралия, США. Исследования в области «экономики изоляции и удаленности», выполненные на материале стран мира, привели к созданию концепций и подходов, применимых и к уровню региона, в той мере, в какой регион можно рассматривать как аналог национальной экономики. Статья посвящена анализу теоретических обоснований эффектов удаленности и результатов их эмпирических проверок. Обсуждаемые эффекты иллюстрируются на примере четырех удаленных республик России: Алтая, Тувы, Бурятии и Хакасии.

Обзор дискуссии на тему «смерть расстояния» показал, что роль последнего в формировании пространственной структуры экономики не снижается, несмотря на развитие технологий транспортировки и телекоммуникаций. Микроэкономический анализ обнаруживает, что в основе поведения фирмы при выборе места размещения производства лежит взаимодействие транспортных затрат и типа экономии от масштаба. На макроэкономическом уровне эти фундаментальные факторы определяют, как влияют параметры удаленности и размера национальной или региональной экономики на показатели производства и благосостояния. В зависимости от соотношения возможны разнонаправленные эффекты: 8 общем случае удаленность экономики снижает эффективность производства, уменьшает конкуренцию и затрудняет распространение инноваций, в то время как растущий размер локального рынка позволяет достигать эффектов масштаба в производстве. Поэтому в удаленных регионах возникает специфическая отраслевая структура экономики, для которой характерны ограниченное число отраслей специализации и гипертрофированная доля государственного сектора из-за трудностей доставки общественных благ.

Основные рекомендации в области региональной политики для преодоления замкнутости удаленных регионов сводятся к поощрению развития инфраструктуры, поддержки локального спроса и развития человеческого капитала, но их потенцииальный положительный эффект ограничен структурными особенностями местных экономик, а долгосрочные последствия повышения транспортной доступности снижают защитный эффект удаленности.

Ключевые слова: удаленность; масштаб экономики; транспортные затраты; экономия на масштабе; региональная политика; Алтай; Тува; Бурятия; Хакасия; малая экономика; региональная экономика

"Работа выполнена по программам фундаментальных научных исследований, определяемых Президиумом РАН.

\section{Для цитирования:}

Мельникова Л. В. Удаленная малая экономика: теоретические основания и эмпирические наблюдения [Электронный ресурс] // Новые исследования Тувы. 2019, № 3. URL: https://nit.tuva.asia/nit/article/view/867 (дата обращения: дд.мм.гг.). DOI: 10.25178/nit.2019.3.8

Мельникова Лариса Викторовна - кандидат экономических наук, доцент, старший научный сотрудник отдела территориальных систем Института экономики и организации промышленного производства Сибирского отделения Российской академии наук. Адрес: 630090, Россия, г. Новосибирск, просп. академика Лаврентьева, д. 17. Тел.: +7 (383) 330-84-67. Эл. адрес: melnikova@ieie.nsc.ru ORCID ID:0000-0001-7427-7289

Melnikova Larisa Melnikova Larisa, Candidate of Economics, Associate Professor, Senior Researcher, Department of Territorial Systems, Institute of Economics and Industrial Engineering, Siberian Branch, Russian Academy of Sciences. Postal address: 17 Akad. Lavrentyev Ave., Novosibirsk, 630090, Russia. Tel.: +7 (383) 3308467.E-mail: melnikova@ieie.nsc.ru 


\title{
A small remote economy: theoretical framework and empirical observations
}

\author{
Larisa V. Melnikova \\ Institute of Economics and Industrial Engineering, Siberian Branch, Russian Academy of Sciences, \\ Russian Federation
}

\begin{abstract}
Since the 1990s, the influence of the geographical factor on the economic dynamics and, hence, inter-country and inter-regional inequality, has been an important focus in the economic literature. The problems of isolated remote regions within a country are relevant for countries distinguished by their size of territory and diversity of natural conditions, such as Russia, Canada, Australia, and the USA. Research in the field of 'economics of isolation and remoteness' carried out on the basis of national economies resulted in the creation of concepts and approaches that are applicable to the level of a region as much as it can be considered analogous to the national economy. The article analyzes some theorizations of the effects of remoteness and the results of empirical tests. The effects discussed are illustrated by the cases of four remote republics: Altai, Tuva, Buryatia and Khakassia.

An overview of the discussion on the 'death of distance' has demonstrated that the role of distance in shaping the spatial structure of economy does not decrease, even though transportation and telecommunication technologies keep improving. A microeconomic analysis reveals that a firm behavior in the course of choosing its location is affected by the interaction between transportation costs and the type of economies of scale. At the macroeconomic level these 2 factors define how the parameters of remoteness and of the size of national or regional economy affect the indicators of production and welfare. Depending on the ratio of these two parameters, multidirectional effects are possible: generally, the remoteness of the economy reduces production efficiency, decreases competition and complicates the spread of innovation, while the growing size of local market results in economies of scale in production. For these reasons, remote regions are distinguished by their specific sectoral structure of economy that is characterized by a small number of sectoral specializations and overgrown share of government sector due to the difficulties in delivering public goods.

Basic recommendations in the field of regional policy aimed to overcome the isolation of remote regions come down to promoting infrastructural development, supporting local demand and developing human capital. However, potential positive impact of such policies is restricted by structural specifics of local economies while long-term effects of enhancing transport accessibility weaken protective effects of remoteness.
\end{abstract}

Keywords: remoteness; size of economy; transportation costs; economies of scale; economy of scale; regional policies; Altay; Tuva; Buryatia; Khakassia; small economy; regional economics

"The article was written under the aegis of programs of fundamental research established by the Presidium of the Russian Academy of Sciences.

For citation:

Melnikova L. V. A small remote economy: theoretical framework and empirical observations. The New research of Tuva. 2019, № 3. URL: https://nit.tuva.asia/nit/article/view/867 (access date ...). DOI: 10.25178/nit.2019.3.8

\section{Введение}

Различия в географическом положении стран могут существенно влиять на потенциал их экономического развития, создавая основу для межстранового неравенства по доходам. Зависимость такого рода представлялась очевидной на начальных этапах развития капитализма, когда могущество государства напрямую увязывалось с возможностями заморской торговли. Неудивительно поэтому, что аргументируя важность размеров рынка для углубления разделения труда, основоположник классической политической экономии А. Смит использовал пример северной Азии как образчик невыгодного положения региона в силу его низкой транспортной доступности: «Вся ... та часть Азии, которая отстоит далеко к северу от Черного и Каспийского морей, древняя Скифия, современная Татария и Сибирь во все века находились, по-видимому, в таком же варварском и диком состоянии, в каком они находятся и в настоящее время. Единственным морем Татарии являлся Ледовитый океан, который не допускает судоходства; и хотя несколько величайших рек в мире протекают по этой стране, они находятся на слишком большом расстоянии друг от друга, чтобы по ним можно было поддерживать сношения и вести торговлю с большей частью страны» (Смит, 2019: 81). 
Тем не менее, в своем дальнейшем развитии основное течение экономической науки преимущественно игнорировало географический фактор. Благодаря Д. Рикардо, который свел различия в местоположении к различиям в плодородности и сделал транспортные издержки неотличимыми от других производственных издержек (Рикардо, 1955), утвердился аргумент, согласно которому различия в размещении неявно учтены в ценах товаров. Эта предпосылка позволяла строить макроэкономические модели национальной и международной экономики и использовать их для анализа и прогноза.

Однако в таких странах как Австралия, Канада, в странах Африки и Океании влияние географического фактора было бы сложно игнорировать. Именно в Австралии, с ее экстремальной удаленностью от Великобритании и Европы, обширной площадью и низкой плотностью населения, в 60-х гг. прошлого века возникло и до сих пор широко используется в национальной дискуссии выражение «тирания расстояния» (Blainey, 2001). В настоящее время влияние расстояния на национальное благосостояние представляется неоспоримым, так что в международной статистике Организации экономического сотрудничества и развития (ОЭСР) удаленные и островные государства выделены в отдельную аналитическую группу. Россия не относится к таким государствам, но размеры ее территории переводят проблему удаленности на внутринациональный уровень, ограничивая возможности смягчения межрегионального неравенства. C другой стороны, в течение последних 20 лет в литературе обсуждалась «смерть расстояния» (Cairncross, 1997; Friedman, 2005) в ходе технического прогресса и отсюда - возможные кардинальные изменения в пространственном распределении человеческой деятельности.

Эта дискуссия далека от завершения и ценна тем, что способствовала теоретическому обоснованию эффектов удаленности и породила множество эмпирических оценок. Далее дан обзор дискуссии и эмпирических проверок аргументов на материалах международной и региональной статистики, рассмотрены эффекты взаимодействия транспортных затрат и типа отдачи от масштаба при выборе фирмой места для размещения производства. В следующем разделе рассмотрены основные каналы воздействия фактора удаленности на национальные и региональные показатели производства и благосостояния. В завершение рассмотрены известные рекомендации в области региональной политики для преодоления замкнутости удаленных регионов. Обсуждаемые эффекты иллюстрируются на примере четырех удаленных российских республик: Алтая, Тувы, Бурятии и Хакасии.

\section{«Смерть расстояния»: эмпирика и микроэкономические основания}

Автор термина «тирания расстояния» Дж. Блейни полагал, что удаленность полностью определила судьбу Австралии, ее экономический и социально-культурный ландшафт. Но 50 лет спустя в тихоокеанском регионе возникли мощные центры экономической активности, так что географическое положение Австралии - уже относительно Японии, Китая, Индии и других стран - стало более конкурентным. Более того, существенное сокращение транспортных тарифов и стремительное развитие телекоммуникационных технологий на рубеже XX-XXI вв. породило оптимизм в отношении перспектив преодоления «сопротивления пространства», что ввело в широкое употребление формулу «смерть пространства» (Cairncross, 1997). В самом деле, с 1930 по 2000 г. стоимость морских перевозок и портовых сборов на тонну груза уменьшилась на две трети, стоимость пассажирских авиаперелетов - почти в 10 раз, а стоимость 3-хминутного телефонного разговора между Нью-Йорком и Лондоном сократилась на 99,9\% (Busse, 2003). Отсюда следовало, что при размещении производства фактор транспортно-коммуникационных затрат должен играть все меньшую роль, фирмы начнут предпочитать периферию центру, так что в перспективе будет происходить дисперсия экономической деятельности в пространстве, соответствующая образу «плоского мира» Т. Фридмана. Последняя идея исходит из перспектив свободного перемещения информации, идей, людей и капиталов в мире, где фактор расстояния теряет значение в силу вышеупомянутых причин (Friedman, 2005).

Эти ожидания вряд ли оправдались, о чем свидетельствует статистика ЮНКТАД (United Nations Conference on Trade and Development, UNCTAD): в течение последних десятилетий доля сектора «Транспорт, хранение и связь» в мировой добавленной стоимости скорее росла, чем снижалась (с 7,8\% в 1970 г. до 8,8\% - в 2017 г. $)^{1}$. Дело в том, что развитие технологий транспортировки сопровождалось не только снижением тарифов, но и изменением их структуры. Развитие поставок «точно в срок» подразумевает уменьшение складских запасов фирм и рост скорости и частоты поставок. Последний фактор влечет за собой увеличение транспортных затрат, но логистические затраты растут превосходящими темпами

${ }^{1}$ https://unctadstat.unctad.org/wds/TableViewer/tableView.aspx?ReportId=95 
в силу возрастающей сложности организации и координации таких поставок. Соответственно, доля транспортной составляющей в трансакционных пространственных издержках снижается, а доля логистической компоненты растет. В структуре информационных издержек снижаются затраты на передачу стандартизованной информации, но возрастание объема и сложности неформализованной информации требует непосредственных контактов между людьми (McCann, Shefer, 2003). Кроме того, доступ к Интернету не равнозначен его повсеместному использованию, о чем свидетельствует рост «цифрового неравенства» в мире, а при прочих равных условиях использование цифровых технологий дает большим городам явные преимущества по сравнению с изолированными регионами. Отсюда следует, что фирма не может быть безразличной к выбору местоположения.

Спустя 20 лет после провозглашения «смерти пространства» можно констатировать, что эта идея не имела достаточно оснований. Если же от микроэкономического анализа затрат фирмы перейти к пространственной структуре расселения, то повсеместно в мире наблюдается растущая концентрация жителей в городах, и это очевидный аргумент не в пользу идеи «плоского мира» (Nijkamp, 2017). На макроэкономическом уровне влияние расстояния на объемы взаимодействий между странами многократно тестировалось на гравитационных моделях. Модели такого типа связывают двухсторонние торговые потоки с размером экономики торгующих стран и с расстоянием между ними с учетом торговых издержек. По аналогии с законом всемирного тяготения предполагается, что чем ближе расположены и экономически крупнее страны, тем больше объемы взаимной торговли. Метаанализ многочисленных опытов тестирования данной гипотезы, предпринятый в работе А.-С. Дидье и К. Хед (Disdier, Head, 2008), позволил привести их к средней оценке эластичности торговли по расстоянию, в соответствии с которой увеличение расстояния между партнерами на 10\% снижает интенсивность двусторонней торговли на 9\%. При этом снижение данного эффекта расстояния происходило в первой половине XX в., а начиная с 50-х гг. наблюдался его рост, что не дает оснований ожидать ослабления влияния фактора пространства на экономическую деятельность.

В этих условиях удаленные и островные экономики оказываются в невыгодной позиции, что в равной степени относится и к удаленным изолированным регионам национальной экономики. В стратегическом анализе географическое положение региона обязательно учитывается с точки зрения вероятных проблем и создаваемых им возможностей. Долгосрочные стратегии развития регионов представляют собой достаточно редкий тип документа, в котором регион выступает как субъект, заявляющий о своем месте и предназначении, оценивающий свои преимущества и слабости. SWOT'-анализ конкурентных позиций удаленных регионов непременно включает в себя и оценку географического положения. Так, в Стратегии социально-экономического развития (далее - СЭР) Республики Тыва до 2030 г. к числу ключевых проблем региона отнесена транспортная изолированность ${ }^{2}$. В Стратегии СЭР Республики Алтай до 2035 г. отмечается, что республика удалена от крупных рынков сбыта, не является центром ни одного рынка, а скорее относится к периферии областей динамичного роста ${ }^{3}$. Хакасский проект Стратегии СЭР до 2030 г. включает удаленность относительно основных экономических центров страны в число слабых конкурентных позиций республики ${ }^{4}$, С Стратегия СЭР Бурятии до 2035 г. - удаленность от морских портов, деловых и культурных центров России 5 .

Следует отметить, что удаленность не сводится к физическому расстоянию, хотя, например, в проекте Стратегии СЭР Хакасии в перечне слабостей приведена цифра «4000 км до Москвы от Абакана». Оценки удаленности, основываясь на гравитационной модели взаимодействий между объектами в пространстве, как правило, учитывают численность населения региона. Разнообразные индексы доступности общественных благ и удаленности региональных сообществ в разрезе городов и регионов разработаны статистическими органами Австралии и Канады (Alasia et al., 2017). Они предназначены для анализа здоровья и благосостояния граждан в зависимости от удаленности с целью более эффективного распределения общественных фондов. Простейшей мерой удаленности является среднее расстояние от административного центра региона до всех остальных, взвешенное по численности населения

${ }^{1}$ Strength, Weakness, Opportunities, Threats - сильные и слабые стороны, возможности и угрозы.

${ }^{2}$ Постановление Правительства Республики Тыва от 24 декабря 2018 года № 638 «О Стратегии социально-экономического развития Республики Тыва до 2030 года». URL: http://docs.cntd.ru/document/550322563

${ }^{3}$ Постановление Правительства Республики Алтай от 13 марта 2018 года № 60 «О Стратегии социально-экономического развития Республики Алтай на период до 2035 года». URL: http://docs.cntd.ru/document/446669488

${ }^{4}$ Проект Стратегии социально-экономического развития Республики Хакасия до 2030 года. URL: https://r-19.ru/management/5697/86042.html

${ }^{5}$ Закон Республики Бурятия от 18 марта 2019 года № 360-VI «О Стратегии социально-экономического развития Республики Бурятия на период до 2035 года». URL: http://docs.cntd.ru/document/553221182 
регионов. Выполнив подобный расчет, мы можем ранжировать столицы вышеназванных субъектов по удаленности, и тогда Горно-Алтайск оказывается на 66-м месте, Абакан - на 70-м, Кызыл - 71-м и УланУдэ - на 73-м месте из 83-х субъектов РФ (без учета Крыма и Севастополя). Взвешивание по объему ВРП не меняет результатов ранжирования. Сравнение строк 4, 5 и 6 таблицы 1 показывает, что учет соседства с крупными рынками сильнее всего сокращает географическую удаленность для Горного Алтая, и практически не оказывает влияния на удаленность Бурятии, в случае которой фактор физического расстояния превалирует.

Таблица 1. Основные характеристики размера экономики и удаленности некоторых субъектов РФ в 2017 г. ${ }^{1}$ Table 1. Basic indicators of the size of the economy and of remoteness for some regions of the RF, 2017.

\begin{tabular}{|c|c|c|c|c|c|c|}
\hline & Показатели & РФ & $\begin{array}{c}\text { Республика } \\
\text { Алтай }\end{array}$ & $\begin{array}{c}\text { Республика } \\
\text { Тыва }\end{array}$ & $\begin{array}{c}\text { Республика } \\
\text { Хакасия }\end{array}$ & $\begin{array}{c}\text { Республика } \\
\text { Бурятия }\end{array}$ \\
\hline 1 & Доля в численности населения РФ, \% & 100 & 0,15 & 0,22 & 0,37 & 0,68 \\
\hline 2 & $\begin{array}{c}\text { Доля в валовом региональном продукте } \\
\text { РФ, \% }\end{array}$ & 100 & 0,06 & 0,08 & 0,26 & 2,28 \\
\hline 3 & $\begin{array}{c}\text { Плотность населения, чел./км }{ }^{2} \\
4\end{array}$ & $\begin{array}{c}\text { Среднее расстояние от столицы региона } \\
\text { до административных центров регионов } \\
\text { РФ, км }\end{array}$ & - & 3712 & 4311 & 3880 \\
\hline 5 & $\begin{array}{c}\text { Удаленность, взвешенная по численности } \\
\text { населения, км }\end{array}$ & - & 3298 & 4017 & 3892 \\
\hline 6 & $\begin{array}{c}\text { Удаленность, взвешенная по объему ВРП, } \\
\text { км }\end{array}$ & - & 3405 & 4126 & 3691 & 4846 \\
\hline
\end{tabular}

Однако ни один из упомянутых удаленных регионов в своей стратегии развития не рассматривает свою позицию, как источник одной лишь слабости. Республика Алтай оценивает свое геостратегическое положение как выгодное из-за близости к регионам нового освоения и к крупным рынкам Сибирского федерального округа таким, как Новосибирск, Кемерово и Барнаул. Близкое соседство Хакасии с крупным высокоразвитым регионом на севере и востоке - Красноярским краем - в стратегии региона оценивается, как создающее стратегические возможности. Бурятия полагает, что занимает выгодное геостратегическое положение, поскольку граничит с Монголией, имеет автомобильные, железнодорожные и водные сообщения. Для Тувы нахождение в географическом центре Азии имеет явное символическое значение, поскольку употреблено в SWOT-анализе как синоним выгодности геостратегического положения, плюсы которого - соседство с Монголией, с республиками Алтай, Хакасия и Бурятия, с Иркутской областью и Красноярским краем.

Для наших целей важно, что анализ стратегических преимуществ в региональных стратегиях добавил к параметру удаленности, помимо физического расстояния, второе измерение - размер соседних экономик, хотя ни один из регионов не назвал очевидно малый размер своей экономики в качестве стратегической слабости. Между тем, доли Горного Алтая, Тувы, Хакасии и Бурятии в валовом региональном продукте Российской Федерации в 2017 г. в сумме составили всего 0,68\% (cм. табл. 1). В самом общем смысле расстояние и размер экономики определяют возможность экономического взаимодействия между регионами. Размер экономики региона измеряют численностью населения, объемом добавленной стоимости или выпуска. Отнеся эти показатели к площади региона, можно оценить плотность экономической деятельности, которая лучше характеризует потенциал взаимодействий внутри регионов и между ними и дает представление уже о внутренней для региона удаленности. С точки зрения плотности населения (строка 3 табл. 1). Хакасия имеет конкурентные преимущества над соседними республиками, плотность населения которых в 3-4 раза ниже среднероссийской.

На микроэкономическом уровне значимость параметров расстояния и размера для региональной экономики обусловлена влиянием двух фундаментальных факторов: наличия транспортных затрат и отдачи от маситаба в производстве. Необходимость оплачивать транспортные издержки вынуждает

! Для расчета использованы данные Федеральной службы государственной статистики РФ - Росстата: http://www.gks.ru/free doc/new_site/vvp/vrp98-17.xlsx; http://www.gks.ru/bgd/regl/b18_14p/IssWWW.exe/Stg/d01/01-01.doc 
фирмы выбирать локации, близкие к рынкам сырья и сбыта. Возрастающая отдача от масштаба в производстве (то есть, более чем пропорциональный рост выпуска при увеличении производственных затрат) стимулирует рост размера предприятия. Результат взаимодействия этих двух факторов - концентрация либо дисперсия экономической деятельности в пространстве - зависит от их соотношения.

Если отдача от масштаба существенная, а транспортные затраты относительно невелики, то фирма может наращивать производство, обслуживая все больший район сбыта и получая сырье от удаленных поставщиков. Происходит концентрация экономической деятельности в локации фирмы. Если транспортные затраты высокие, то это накладывает ограничение на рост фирмы. Нет смысла увеличивать масштабы производства, если возникающая экономия от масштаба будет поглощаться ростом транспортных затрат на доставку товаров удаленным потребителям. Поэтому фирма теряет стимул к экспансии, ее доля рынка сокращается, на рынке появляются фирмы-конкуренты, следовательно, происходит дисперсия экономической деятельности в пространстве. В случае постоянной отдачи от масштаба поведение фирмы будет определяться только уровнем транспортных затрат, а следовательно, стремлением, ради экономии, разместиться ближе к потребителям и производственным факторам, и тогда пространственное распределение экономической деятельности будет целиком определяться их размещением.

Однако все сказанное выше относилось к внутренней отдаче от масштаба, которую может получить одна фирма. Если в одной локации размещается несколько фирм, то они могут получить внешнюю экономию от масштаба, называемую локализационной. Внешние эффекты при концентрации фирм, производящих одинаковый продукт, включают в себя экономию при поиске квалифицированного труда, при координации поставок и сбыта, при получении информации, при использовании специализированных услуг и инфраструктуры. Если фирмы принадлежат разным отраслям, но связаны участием в едином производственном процессе, то их выигрыш состоит в экономии на транспортных затратах и координации производственного процесса. Если же в одной локации собираются фирмы, производящие разнообразные продукты, их поставщики и обслуживающие фирмы, которые могут предоставлять услуги только при значительном объеме спроса (это, например, финансовые, образовательные услуги и т. п.), то возникает урбанизационная отдача от масштаба. Возможность получить внешние эффекты масштаба на уровне отрасли и города будет стимулировать фирмы к сосредоточению в пространстве даже в условиях высоких транспортных затрат, а находясь в кластере, фирмы могут далее нарастить масштаб производства и расширить рынок сбыта (Мельникова, 2015).

\section{Взаимодействие параметров расстояния и размера как фактор успеха региональной экономики}

Из теории размещения не следует прямо, что большие экономики, близко размещенные друг к другу, будут более успешными. Экономика страны не сводится к сумме фирм, рационально действующих в условиях совершенной информации, руководствуясь тем или иным критерием оптимизации. Район сбыта, который может обслужить фирма в силу своего масштаба, может быть больше территории региона или страны, но может быть разделен государственными границами.

Направление анализа, известное как «экономика изоляции и удаленности» (Redding, Venables, 2002: Электр. ресурс), возникло в рамках теории международной торговли, рассматривающей государства как единицы анализа. Такой подход позволяет оценить прямые и косвенные издержки удаленности эмпирически, на базе международной статистики. К прямым последствиям удаленности относят те, что следуют из роста транспортных затрат: сокращение объемов экспорта и импорта, прямых иностранных инвестиций, потоков финансовых активов и технологий. В удаленных регионах мира уровень транспортных затрат существенно выше, чем на основных торговых путях с высокой плотностью траффика. Уровень транспортной наценки можно косвенно оценить, рассчитав соотношение стоимости импорта в ценах CIF и FoB ${ }^{1}$. Например, в 2016 г. данный показатель составлял в США 2,7\%, в Бразилии - 4,4\%, в Южной Африке - 5,2\%, в Исландии - 6,5\% и в России - 10\%². В особенно невыгодном положении оказываются страны, не имеющие выхода к морю, что лишает их возможности пользоваться самым дешевым морским транспортом и ставит в зависимость от услуг транзитных государств (MacKellar,

${ }^{1}$ Цена CIF (Cost, Insurance, Freight) включает в себя затраты на транспортировку до пункта назначения, тогда как цена FoB (Free on Board) - лишь до пункта погрузки.

${ }^{2}$ Рассчитано по данным IMF. International Financial Statistics Yearbook, 2018. URL: http://data.imf.org/?sk=edcb50d2-9c8a-4d3d8b4f-190d2e4be644 
Wörgötter, Wörz, 2000: Электр. pесурс). В то же время развитие поставок «точно в срок» побуждает к использованию авиатранспорта и контейнеризации и увеличивает альтернативную стоимость времени, затрачиваемого на перевозки. Непрямой эффект удаленности - снижение уровня ВВП на душу населения и темпов экономического роста. Эта гипотеза, основанная на предпосылке о том, что необходимость оплачивать транспортные расходы сокращает способность фирмы оплачивать услуги труда, была неоднократно тестирована на материале национальных экономик. Достаточно сказать, что размер ВВП на душу населения в развивающихся странах, не имеющих выхода к морю (по методологии ЮНКТАД в эту группу входят 33 государства, такие как Афганистан, Казахстан, Монголия и др.), в 2017 г. составлял в среднем 36\% к уровню душевого ВВП в группе 164 развивающихся стран (без Китая)ํ.

В теоретическом анализе удаленности выделяются такие темы, как эффективность производства, конкуренция и проблемы распространения инноваций, структурные особенности удаленных экономик и проблемы доставки общественных благ. Методологическую основу анализа составляют закономерности поведения фирм и потребителей в процессе выбора своего местоположения, которые тестируются на уровне как стран, так и регионов, с учетом известных отличий региональной экономики от национальной, таких как бо́льшая открытость, меньший размер экономики, высокий уровень специализации, пониженные институциональные барьеры, участие в межбюджетных отношениях федерального государства.

Продуктивность экономики в самом общем смысле - как отношение выпуска к затратам - подвержена влиянию удаленности в той мере, в какой выпуск и затраты фирмы в удаленном регионе страны (или мира) отличаются от средних в национальной (или мировой) экономике. Фактор удаленности будет воздействовать на эффективность негативно, если выпуск будет сокращаться, либо затраты - расти. Чтобы производить эффективно, фирма, независимо от ее местонахождения, должна осуществлять производство в таких масштабах, чтобы ее удельные издержки снижались. Если регион пребывания способен обеспечить такой спрос, то фирма успешно обслуживает локальный рынок, что обычно справедливо в отношении стандартных, несложных товаров (для которых характерна невысокая отдача от масштаба в производстве). Но в случае высокотехнологичных и инновационных товаров достижение эффекта масштаба требует больших объемов спроса, которые фирма сможет найти только на национальном и международном рынках, и тогда критически важной становится доступность рынков, т. е. возможность достичь их с минимальными транспортными затратами. В этом случае размещение фирмы в географически удаленном регионе подразумевает дополнительные затраты как на транспортировку грузов, так и на обеспечение координации с поставщиками и потребителями, что поднимает уровень средних издержек. Соответственно, фирма не достигает того эффекта масштаба, который имеют ее конкуренты в более выгодных локациях.

Показано, например, что хроническое отставание производительности труда в австралийских штатах по сравнению с североамериканскими в значительной степени объясняется географическим фактором, т. е. удаленностью австралийской экономики от мировых рынков (Battersby, 2006: Электр. ресурс). В свою очередь, еще более изолированная экономика Новой Зеландии уступает по производительности труда австралийской, и этот разрыв на 50\% объясняется фактором расстояния ${ }^{2}$. Ф. Макканн отмечает, что Новая Зеландия демонстрирует неблагоприятное сочетание малого масштаба экономики и экстремальной географической удаленности. При этом сравнимая по удаленности Австралия компенсирует невыгоды своего местоположения масштабом и диверсифицированностью национальной экономики, а сравнимые по размеру экономики Ирландии, Швеции, Дании и других малых европейских стран преуспевают в диверсификации экспорта благодаря близости к большим рынкам. Таким образом, быть малой и изолированной страной означает иметь ограниченные возможности по достижению отдачи от масштаба (McCann, 2009).

С другой стороны, конкуренты извне, приходящие в удаленную страну или регион, теряют конкурентоспособность на локальном рынке, так как вынуждены увеличивать издержки на преодоление расстояния. В результате деятельность местных фирм может оказаться вполне прибыльной, даже если им не удается достичь полной отдачи от масштаба. Снижение числа игроков относительно потенциального уменьшает конкуренциию на рынке. Расстояние выполняет в данном случае роль защитного барьера, делая экономику более закрытой, что не способствует повышению эффективности производства.

${ }^{1}$ https://unctadstat.unctad.org/wds/TableViewer/tableView.aspx?ReportId=96

${ }^{2}$ IMF (2004) New Zealand: Selected issues // IMF Country Report. № 127(4). 28 p. URL: https://www.imf.org/external/pubs/ft/scr/2004/ cr04127.pdf 
Отмеченный защитный эффект удаленности наблюдался и в долгосрочной исторической перспективе. На базе выборки стран Старого света в период до изобретения современных транспортных средств К. Ашраф и др. обнаружили статистически значимый и устойчивый положительный эффект степени изоляции страны на уровень ее экономического развития (Ashraf, Galor, Ozak, 2010). Вероятно, изоляция некоторых стран побуждала независимое развитие технического прогресса, способствовала созданию устойчивой культурной среды, способствующей инновациям, о чем свидетельствуют, например, неоспоримые технические достижения Китая в период его политики добровольного изоляционизма. Кроме того, защищенные пространством удаленные страны получали отсрочку от вторжения технически превосходящих государств, что давало возможность накопления и распределения ресурсов на инновации.

Положительное влияние географической близости на распространение инноваций следует из модели пространственной диффузии инноваций Т. Хагерстранда (Hägerstrand, 1967)). В этой модели используется теория центральных мест для того, чтобы обосновать два канала распространения инноваций в пространстве. Первый из них подразумевает концентрацию инноваций в городах высшего ранга с последующим переливом на нижние уровни городской системы, второй канал передачи инноваций основан на непосредственных контактах между соседними городами одного иерархического уровня. K настоящему времени сложилось общее убеждение в том, что географическая удаленность затрудняет диффузию инноваций в пространстве и тормозит, таким образом, развитие удаленных регионов. Известны оценки, согласно которым влияние накопленных вложений в исследования и разработки на совокупную факторную производительность тем слабее, чем более удалена экономика от основной массы рынков (Redding, Venables, 2002: 95).

Фактор удаленности оказывает неоднозначное влияние на структуру экономики, в частности на уровень ее специализации и стабильность отраслевой структуры. В условиях постоянной отдачи от масштаба два региона могут иметь одинаковые сравнительные преимущества в производстве некоего товара, но если в более удаленном регионе эти преимущества поглощаются транспортными издержками, то такой товар не будут производить в масштабах, превосходящих локальный спрос. В результате будет производиться большее число товарных позиций с меньшей эффективностью, объемы межрегиональной торговли будут снижаться. Если же производство характеризуется возрастающей отдачей от масштаба, позволяющей компенсировать рост транспортных затрат, то происходит рост уровня специализации, при условии, что объем внешнего спроса достаточен. Какой бы малой и удаленной ни была местная экономика, в ней всегда обнаруживаются товары, район сбыта которых превосходит площадь региона. В таблице 2 приведен перечень видов деятельности с наивысшими показателями специализации в республиках Алтай, Тыва, Хакасия и Бурятия. Уровень специализации оценивается с помощью коэффициента локализации, который представляет собой отношение доли отрасли в региональной экономике к одноименной доле в национальной экономике, размер которой может быть измерен показателями, занятости, добавленной стоимости и т. п. Значение коэффициента, большее 1, указывает на то, что концентрация экономической деятельности в данной отрасли в данном регионе превосходит средний уровень концентрации в стране. Значения меньше единицы в таблице опущены.

Таблица 2. Коэффициенты локализации производства в некоторых субъектах РФ в 2017 г. ${ }^{1}$ Table 2. Localization quotients for some regions of the RF, 2017.

\begin{tabular}{|c|c|c|c|c|}
\hline Виды экономической деятельности & $\begin{array}{l}\text { Республика } \\
\text { Алтай }\end{array}$ & $\begin{array}{l}\text { Республика } \\
\text { Тыва }\end{array}$ & $\begin{array}{l}\text { Республика } \\
\text { Хакасия }\end{array}$ & $\begin{array}{l}\text { Республика } \\
\text { Бурятия }\end{array}$ \\
\hline Животноводство & 3,1 & & & \\
\hline $\begin{array}{l}\text { Деятельность вспомогательная в производстве сельхозкультур и } \\
\text { послеуборочной обработки продукции }\end{array}$ & 1,2 & 1,3 & 2,7 & \\
\hline Лесоводство и прочая лесохозяйственная деятельность & 12,7 & & 2,2 & 1,2 \\
\hline $\begin{array}{l}\text { Сбор и заготовка пищевых и недревесных лесных ресурсов, } \\
\text { лекарственных растений }\end{array}$ & & & & 9,7 \\
\hline
\end{tabular}

${ }^{1}$ Для расчета использованы данные Росстата о среднесписочной численности работников по полному кругу организаций. URL: https://fedstat.ru/indicator/58699?id=58699 


\begin{tabular}{|c|c|c|c|c|}
\hline Предоставление услуг в области лесоводства и лесозаготовок & 3,1 & 3,0 & & 9,8 \\
\hline Рыбоводство & & & 1,5 & 3,1 \\
\hline Добыча и обогащение угля и антрацита & & 4,5 & 10,5 & \\
\hline Добыча и обогащение бурого угля (лигнита) & & & & 4,6 \\
\hline Добыча и обогащение железных руд & & & 3,2 & \\
\hline Добыча руд цветных металлов & 4,2 & 10,9 & 8,0 & 8,4 \\
\hline Производство готовых кормов для животных & 2,7 & & & \\
\hline Производство пива & & & 6,3 & \\
\hline Производство бумаги и картона & & & & 7,3 \\
\hline Производство цемента, извести и гипса & & & & 2,2 \\
\hline Резка, обработка и отделка камня & & & 3,5 & \\
\hline $\begin{array}{l}\text { Производство основных драгоценных металлов и прочих } \\
\text { цветных металлов, ядерного топлива }\end{array}$ & & & 6,4 & \\
\hline Производство прочих машин специального назначения & & & 4,6 & \\
\hline $\begin{array}{l}\text { Производство кузовов для автотранспортных средств; прицепов } \\
\text { и полуприцепов }\end{array}$ & & & 4,0 & \\
\hline $\begin{array}{l}\text { Производство железнодорожных локомотивов и подвижного } \\
\text { состава }\end{array}$ & & & & 7,0 \\
\hline Производство летательных аппаратов & & & & 4,1 \\
\hline Производство медицинских инструментов и оборудования & & & & 2,2 \\
\hline $\begin{array}{l}\text { Деятельность железнодорожного транспорта: междугородные и } \\
\text { международные пассажирские перевозки }\end{array}$ & & & 1,5 & 3,1 \\
\hline
\end{tabular}

Данные таблицы 2 демонстрируют, что даже в случае малого масштаба экономики относительный размер не теряет значения. В алтайской, тувинской, хакасской и бурятской экономиках трудятся соответственно - 0,1, 0,2, 0,3 и 0,5\% занятых РФ. Пропорционально размеру республик в них растет и число видов специализации: 5, 4, 12 и 12. При этом специализация на товарах, отличающихся возрастающей отдачей от масштаба в производстве (продукты машиностроения, услуги транспорта), наблюдается в более крупных Хакасии и Бурятии. В то же время во всех республиках наиболее выражены преимущества регионов в видах деятельности, основанных на доступности локализованных минеральных и лесных ресурсов.

Особенность добывающего производства состоит в том, что предельный масштаб производства задается на начальной стадии освоения месторождения (Cairns, 1998). По мере роста объемов добычи и приближения к ограничению по запасам возрастающая отдача от масштаба сменяется убывающей. С точки зрения размещения фирмы это подразумевает, что, во-первых, при входе в регион она учитывает не географическую, а экономическую (т. е. с учетом затрат и выгод) удаленность, которая определяется конъюнктурой внешнего рынка, а во-вторых, что срок ее пребывания на территории региона ограничен сроком исчерпания добываемых ресурсов. С учетом ограниченности локальных производственных факторов в экономике малого региона, возникает структурная ловушка: чем выше доля добывающей промышленности, тем у́же возможности достижения внешних эффектов масштаба, тем меньше оснований ожидать кластеризации фирм в отраслях переработки и услуг, проигрывающих сектору добычи при оценке их сравнительных преимуществ. Кроме того, в случае колебаний конъюнктуры внешнего спроса возможны резкие изменения отраслевой номенклатуры производства. Существует также проблема асимметрии во взаимоотношениях региональной администрации и крупной корпорации, действующей на территории. 
Специфическая для структуры малой региональной экономики черта - гипертрофированная доля государственного сектора, что отражает особенности доставки общественных благ в редконаселенном пространстве. Обязательства, которые берет на себя правительство в отношении пространственного равенства, подразумевают предоставление гарантированного минимума медицинского обслуживания, образования, социальных услуг, коммунальной и общественной инфраструктуры, безопасности всем гражданам, независимо от региона проживания. Соответственно, доступность этих благ определяется, в первую очередь, их транспортной и пешеходной доступностью, и, несмотря на стремление правительства оптимизировать сеть социальных учреждений, их размещение определяется скорее социальными нормативами, чем теориями размещения фирмы. На основании данных таблицы 3 можно предположить, что доля общественных услуг в экономике региона находится в обратной зависимости от его размера.

Таблица 3. Доля отдельных видов нерыночных видов услуг в занятости в некоторых субъектах РФ в 2017 г., $\%$ к сумме видов деятельности 1 .

Table 3. Contributions of some non-market services into the total employment in some regions of the RF in 2017,

$\%$ of the total.

\begin{tabular}{|l|c|c|c|c|c|}
\hline \multicolumn{1}{|c|}{ Виды экономической деятельности } & РФ & $\begin{array}{c}\text { Республика } \\
\text { Алтай }\end{array}$ & $\begin{array}{c}\text { Республика } \\
\text { Тыва }\end{array}$ & $\begin{array}{c}\text { Республика } \\
\text { Хакасия }\end{array}$ & $\begin{array}{c}\text { Республика } \\
\text { Бурятия }\end{array}$ \\
\hline $\begin{array}{l}\text { Государственное управление и обеспечение } \\
\text { военной безопасности; социальное } \\
\text { обеспечение }\end{array}$ & $7,9 \%$ & $18,6 \%$ & $19,4 \%$ & $12,8 \%$ & $14,0 \%$ \\
\hline Образование & $11,4 \%$ & $24,7 \%$ & $32,8 \%$ & $17,1 \%$ & $14,4 \%$ \\
\hline $\begin{array}{l}\text { Деятельность в области здравоохранения и } \\
\text { социальных услуг }\end{array}$ & $9,3 \%$ & $14,3 \%$ & $17,5 \%$ & $12,0 \%$ & $13,0 \%$ \\
\hline $\begin{array}{l}\text { Деятельность в области культуры, спорта, } \\
\text { организации досуга и развлечений }\end{array}$ & $1,9 \%$ & $3,4 \%$ & $4,1 \%$ & $2,3 \%$ & $2,3 \%$ \\
\hline $\begin{array}{l}\text { Научные исследования и разработки в области } \\
\text { общественных и гуманитарных наук }\end{array}$ & $0,04 \%$ & $0,05 \%$ & $0,14 \%$ & $0,03 \%$ & $0,10 \%$ \\
\hline $\begin{array}{l}\text { Деятельность в области художественного } \\
\text { творчества }\end{array}$ & $0,04 \%$ & - & $0,42 \%$ & $0,003 \%$ & $0,02 \%$ \\
\hline
\end{tabular}

Помимо России, проблема поставки общественных благ в удаленные регионы типична и для других обширных стран, таких как Австралия, США, Канада. Если в Австралии в секторе государственного управления, обязательного среднего образования и здравоохранения в 2017 г. работали 27\% занятых, то в регионе Северная территория в этой сфере трудились 37\%. Аналогичный показатель по США в целом составил $25 \%$, а на Аляске - $35 \%$; по Канаде в целом $25 \%$, а в регионе Ньюфаундленд и Лабрадор - $30 \% 2$.

Нельзя не заметить, что на фоне рассматриваемых регионов Республика Тыва выделяется повышенной долей занятых научными гуманитарными исследованиями и художественным творчеством. Относительный размер этих отраслей оказывается в 10 раз больше среднероссийского, что нельзя объяснить одним лишь малым масштабом экономики. Это наблюдение перекликается с результатами исследования профессиональных предпочтений тувинцев (Дабиев, 2018: Электр. ресурс).

\section{Заключение}

Инструменты региональной политики, предназначенные для преодоления последствий удаленности и малости региона, хорошо известны. Проведенный анализ позволяет не только прояснить теоретические основания этих инструментов, но и оценить возможные последствия их осуществления.

Безусловно, первым из популярных инструментов региональной политики является содействие развитию региональной инфраструктуры, что помогает фирмам снижать производственные затраты. Эта рекомендация основана на том, что источником роста является предложение производственных

\footnotetext{
1 Для расчета использованы данные Росстата о среднесписочной численности работников по полному кругу организаций. URL: https://fedstat.ru/indicator/58699?id=58699

${ }^{2}$ Рассчитано на основе данных OECD.Stat. URL: https://stats.oecd.org/\#
} 
факторов. Как мы уже писали ранее в другой работе, в частности, строительство транспортной инфраструктуры, развитие энергетики, систем передачи информации является привлекательным фактором для размещения фирм, равно как и развитие систем переобучения, повышения квалификации, трудоустройства и поощрения карьерного роста. Кроме того, политика администрации при выделении земельных участков для экономической деятельности, программы рекультивации и реновации участков прямо влияют на их стоимость. Способствуют снижению затрат и меры, облегчающие приток и распространение знаний в регионе: поддержка научных и технологических парков, бизнес-инкубаторов, финансирование грантовых программ и субсидирование кредитов (Мельникова, 2018). В результате экономическое расстояние между регионами сокращается.

Но инфраструктурные отрасли, особенно транспорт и энергетика, для эффективного функционирования также должны достигать эффекта масштаба. Здесь возникает ограничение со стороны размера рынка малого региона. Само по себе развитие инфраструктуры не принесет рост в регион, если не наберется достаточного количества пользователей и устойчивых объемов спроса, в первую очередь, со стороны отраслей специализации, эффекты масштаба в которых мы рассмотрели выше. Более того, защитный эффект пространства может ослабеть, так как возросшая транспортная доступность региона может привлечь в него более эффективные фирмы, с которыми местные производители не смогут конкурировать.Повысится и конкуренция за трудовые ресурсы среди работодателей, так как работники могут с легкостью покинуть родной регион. Таким образом, развитие инфраструктуры удаленного региона является необходимым, но далеко не достаточным условием преодоления «тирании расстояния».

Второй широко используемый инструмент региональной политики состоит в поощрении регионального спроса и основан на мультипликативном эффекте государственных расходов. Государственные программы поддержки местного бизнеса создают запрос на дополнительные трудовые ресурсы; содействие занятости и меры социальной поддержки через рост доходов домохозяйств повышают спрос на местные товары; программы строительства инфраструктуры разгоняют рост строительства и промышленности строительных материалов. Поэтому администрации стремятся привлечь в регион крупные фирмы и одновременно выдвигают условия по локализации производства. Зачастую региональные власти конкурируют за право проведения крупных спортивных или юбилейных событий в регионе, ожидая роста федеральных расходов на территории.

Вместе с тем из нашего анализа следует, что отрасли специализации, выбираемые для государственной поддержки в удаленных регионах, должны отвечать таким критериям, как невысокая транспортоёмкость и возможность получать внешнюю отдачу от масштаба. Развитие таких отраслей страхует регион от роста транспортной составляющей в структуре затрат. Также повышается вероятность появления многоотраслевых кластеров, а, следовательно, устойчивость региона к воздействию внешних шоков. Что касается мер по стимулированию спроса, то повышение доходов бедных слоев населения, доля которых, как правило, высока в удаленных малых регионах, приводит к росту, в первую очередь, потребительского спроса. Поэтому мультипликативный эффект такой политики ограничен скудостью отраслевой структуры местной экономики и будет удовлетворяться, большей частью, поставками извне.

Наконец, в региональной политике часто рекомендуется развитие «человеческого капитала», т. е. повышение уровня образованности работников, стимуляция стартапов, поощрение распространения знаний и навыков. Именно в сфере накопления информации и распространения инноваций «тирания расстояния» стремительно ослабевает благодаря новым технологиям, что дает наибольший относительный эффект в удаленных регионах. С другой стороны, в защищенных расстоянием регионах важны местные особенности, формирующие уникальный социальный капитал территории, сохранение и культивирование которого способствует раскрытию потенциала региона и сокращению экономической «дистанции» между ним и регионами-лидерами.

\section{СПИСОК ЛИТЕРАТУРЫ}

Дабиев, Д. Ф. (2018) Профессиональные предпочтения населения Тувы в контексте экономической культуры [Электронный ресурс] // Новые исследования Тувы. № 2. C. 132-148. DOI: 10.25178/nit.2018.2.7

Мельникова, Л. В. (2015) Современная региональная экономика: теории и модели. Новосибирск : Издательство НГУ. 303 с.

Мельникова, Л. В. (2018) Теоретические аргументы и эмпирическое знание в стратегическом планировании // Регион: экономика и социология. № 2(98). С. 52-81. DOI: 10.15372/REG20180203. 
Рикардо, Д. (1955) Начала политической экономии и налогового обложения // Рикардо, Д. Сочинения : в 4 т. М. : Государственное издательство политической литературы. Т. I. 860 с.

Смит, А. (2019) Исследование о природе и причинах богатства народов : пер. с англ. М. : Эксмо. 960 с.

Alasia, A., Bédard, F., Bélanger, J., Guimond, E., Penney, Ch. (2017) Measuring remoteness and accessibility: A set of indices for Canadian communitiess (Reports on Special Business Projects No. 18-001-X) [Электронный pecypc] // Statistics Canada. URL: http://www.statcan.gc.ca/pub/18-001-x/18-001-x2017002-eng.htm (дата обращения: 20.05.2019)

Ashraf, Q., Galor, O., Ozak, O. (2010) Isolation and Development // Journal of the European Economic Association. № 2-3(8). P. 401-412. DOI: 10.1111/j.1542-4774.2010.tb00511.x

Battersby, В. (2006) Does distance matter? The effect of geographic isolation on productivity levels [Электронный ресурс] // OECD Economic Studies. № 42. P. 205-225. URL: http://www.oecd.org/australia/38698291. pdf. (дата обращения: 10.05.2019).

Blainey, G. (2001) The tyranny of distance: how distance shaped Australia's history. Sydney : Macmillan. $413 \mathrm{p}$.

Busse, M. (2003) Tariffs, Transport Costs and the WTO Doha Round: The Case of Developing Countries [Электронный ресурс] // The Estey Centre Journal of International Law and Trade Policy. № 1(4). Pp. 15-31. URL: https://ideas.repec.org/a/ags/ecjilt/23818.html (дата обращения: 13.05.2019)

Cairncross, F. (1997) The death of distance: how the communications revolution is changing our lives. Boston, MA. : Harvard Business School Press. 302 p.

Cairns, R. D. (1998) The microeconomics of mineral extraction under capacity constraints // Nonrenewable Resources. № 3(7). P. 233-244. DOI: 10.1007/BF02767673

Disdier, A.-C., Head, K. (2008) The Puzzling Persistence of the Distance Effect on Bilateral Trade // The Review of Economics and Statistics. № 1(90). P. 37-48. DOI: 10.1162/rest.90.1.37

Friedman, T. L. (2005) The world is flat: a brief history of the twenty-first century. New York: Farrar, Straus and Giroux. 488 p.

Hägerstrand, T. (1967) Innovation Diffusion as a Spatial Process. Chicago, IL: University of Chicago Press. $357 \mathrm{p}$.

MacKellar, L., Wörgötter, A., Wörz, J. (2000) Economic Development Problems of Landlocked Countries [Электронный ресурс] // Reihe Transformationsökonomie / Transition Economics Series. № 14. Vienna: Institute for Advanced Studies. URL: https://www.ihs.ac.at/publications/tec/te-14.pdf (дата обращения: 11.05.2019).

McCann, Ph. (2009) Economic geography, globalisation and New Zealand's productivity paradox // New Zealand Economic Paper. № 3(43). P. 279-314. DOI: 10.1007/s10110-003-0182-y

McCann, Ph., Shefer, D. (2003) Location, agglomeration and infrastructure // Papers in Regional Science. № 1(83). P. 177-196. DOI: 10.1080/00779950903308794

Nijkamp, P. (2017) The Death of Distance // Economic Ideas You Should Forget / Frey B. S., Iselin D. (eds.). Cham : Springer International Publishing. 166 p. DOI: 10.1007/978-3-319-47458-8

Redding, S., Venables, A. J. (2002) The Economics of Isolation and Distance [Электронный ресурс] // Nordic Journal of Political Economy. № 28. P. 93-108. URL: http://www.nopecjournal.org/NOPEC_2002_a07.pdf (дата обращения: 21.05.2019).

Дата поступления: 28.05.2019 2.

\section{REFERENCES}

Dabiev D. F. (2018) Professional'nye predpochtenia naselenia Tuvy v kontekste ekonomicheskoi kul'tury [Career preferences of Tuva population in the context of economic culture]. The New Research of Tuva, no. 2, pp. 132-148. (In Russ.) DOI: 10.25178/nit.2018.2.7

Mel'nikova, L. V. (2015) Sovremennaia regional'naia ekonomika: teorii i modeli [Modern regional economies: Theories and models]. Novosibirsk, NSU Publ. (In Russ.)

Mel'nikova, L. V. (2018) Teoreticheskie argumenty i jempiricheskoe znanie v strategicheskom planirovanii [Theoretical arguments and empirical evidence in strategic planning]. Region: ekonomika $i$ sotsiologia [Region: Economics and Sociology], vol. 98, no. 2, pp. 52-81. (In Russ.) DOI: 10.15372/REG20180203 
Ricardo, D. (1955) Nachala politicheskoi ekonomii i nalogovogo oblozheniia [On the principles of political economy and taxation]. In: Ricardo, D. Sochineniia [Works]. Moscow, Gosudarstvennoe izdatelstvo politicheskoi literaturi. Vol. I. 860 p. (In Russ.)

Smith, A. (2019) Issledovanie o prirode i prichinah bogatstva narodov [An inquiry into the nature and causes of the wealth of nations]. Moscow, Jeksmo Publ. (In Russ.)

Alasia, A., Bédard, F., Bélanger, J., Guimond, E. and Penney, Ch. (2017) Measuring remoteness and accessibility: A set of indices for Canadian communitiess (Reports on Special Business Projects No. 18- 001-X). Statistics Canada [online] Available at: http://www.statcan.gc.ca/pub/18-001-x/18-001-x2017002-eng.htm (access date: 20.05.2019)

Ashraf, Q., Galor, O. and Ozak, O. (2010) Isolation and Development. Journal of the European Economic Association, April-May, vol. 8, no. 2-3, pp. 401-412. DOI: 10.1111/j.1542-4774.2010.tb00511.x.

Battersby, B. (2006) Does distance matter? The effect of geographic isolation on productivity levels. OECD Economic Studies, no. 42, pp. 205-225 [online] Available at: http://www.oecd.org/australia/38698291.pdf (access date: 10.05 .2019$)$

Blainey, G. (2001) The tyranny of distance: how distance shaped Australia's history. Sydney, Macmillan. 413 p.

Busse, M. (2003) Tariffs, transport costs and the WTO Doha Round: The case of developing countries. The Estey Centre Journal of International Law and Trade Policy, vol. 4, no. 1, pp. 15-31 [online] Available at https://ideas. repec.org/a/ags/ecjilt/23818.html (access date: 13.05.2019).

Cairncross, F. (1997) The death of distance: how the communications revolution is changing our lives. Boston, MA, Harvard Business School Press. 302 p.

Cairns, R. D. (1998) The microeconomics of mineral extraction under capacity constraints. Nonrenewable Resources, September, vol. 7, no. 3, pp. 233-244. DOI: 10.1007/BF02767673

Disdier, A.-C. and Head, K. (2008) The puzzling persistence of the distance effect on bilateral trade. The Review of Economics and Statistics, vol. 90, no. 1, pp. 37-48. DOI: 10.1162/rest.90.1.37

Friedman, T. L. (2005) The world is flat: a brief history of the twenty-first century. New York, Farrar, Straus and Giroux. 488 p.

Hägerstrand, T. (1967) Innovation diffusion as a spatial process. Chicago, IL, University of Chicago Press.

MacKellar, L., Wörgötter, A. and Wörz, J. (2000) Economic growth of landlocked countries. Reihe Transformationsökonomie / Transition Economics Series, no. 14. Institute for Advanced Studies [online] Available at https:// ideas.repec.org/p/ihs/ihstep/14.html (access date: 11.05.2019).

McCann, P. (2009) Economic geography, globalisation and New Zealand's productivity paradox. New Zealand Economic Paper, vol. 43, no. 3, pp. 279-314. DOI: 10.1080/00779950903308794

McCann, P. and Shefer, D. (2003) Location, agglomeration and infrastructure. Papers in Regional Science, vol. 83, no. 1, pp. 177-196. DOI: 10.1007/s10110-003-0182-y

Nijkamp, P. (2017) The death of distance. In: B. S. Frey and D. Iselin, eds. Economic ideas you should forget. Cham, Springer International Publishing, pp. 93-94. DOI: 10.1007/978-3-319-47458-8

Redding, S. and Venables, A. J. (2002) The economics of isolation and distance. Nordic Journal of Political Economy, vol. 28, pp. 93-108 [online] Available at: http://www.nopecjournal.org/NOPEC_2002_a07.pdf (access date: 21.05 .2019$)$.

Submission date: 28.05.2019. 